\title{
Marett og mana
}

\author{
TOVE TYBJERG
}

\begin{abstract}
ENGLISH ABSTRACT: Robert Ranulph Marett's (1866-1943) name is closely identified with the mana-concept. In some influential essays around 1900 and in critical dialogue with Tylor and Frazer, Marett proposed to use 'mana' as a technical term. Many were persuaded by Marett's argument, but used the mana-concept in such a broad and heterogenous way, that it was soon deemed unfit for scientific use. As a result of Marett being more or less forgotten afterwards, few have been aware, that Marett's arguments are more sophisticated than is usually acknowledged. Danish historians of religion have taken a more vivid interest in mana and the mana-concept; on a different basis, some of the issues - discussed in Denmark in connection with the mana-concept - are now under debate in 'New animism'.
\end{abstract}

DANSK RESUME: Robert Ranulph Maretts (1866-1943) navn er tæt knyttet til begrebet mana. I kritisk dialog med Tylor og Frazer argumenterede Marett i nogle skelsættende essays omkring år 1900 for indførelse af mana som teknisk term. Mange tog mana-begrebet til sig, men anvendte det så bredt og forskelligartet, at det hurtigt blev anset for ubrugeligt. At Marett siden blev mere eller mindre glemt, har medført, at man $i$ almindelighed ikke har været tilstrækkelig opmærksom på nuancerne i Maretts argumentation. Det gælder dog ikke i dansk religionsvidenskab, hvor diskussionen af mana og mana-begrebet har været mere omfattende; problemstillinger, som i Danmark blev drøftet $i$ forbindelse med mana-begrebet, er på et andet grundlag til diskussion i nutidens 'New animism'.

KEYWORDS: Mana-concept; Marett; Tylor; Frazer; Evolution; Emotions; New animism

"Af grundlæggende betydning er begrebet mana" stod der på en af de første sider i min gymnasietids religionsbog (Hvidtfeldt 1961, 12). At blive præsenteret for et for os gymnasieelever ganske nyt og ukendt "grundlæggende" begreb, der med et slag gav mulighed for at se religion - især den såkaldt "primitive" - som gennemskuelig, logisk og forståelig var inciterende og øjenåbnende. Bogen hed Religioner og kulturer (1961); dens første sætning lød "Religion er en samfundsforeteelse"; den var skrevet af vores lærer, den senere professor i religionssociologi, dr. phil. Arild Hvidtfeldt; den var rød og fik i de sene 1960'ere blandt kendere betegnelsen 'Arilds lille røde'. 
Ungdommelig begejstring har det med at blive tempereret, og religionsvidenskabeligt er det nok især forskningshistorien, der giver anledning til en tempererende refleksion. Læser man det tidlige 1900-tals religionsforskere, opdager man, at de fra en ende af mente, at begrebet mana var af 'grundlæggende betydning', men også, at det ikke var samme 'grundlæggende betydning', de lagde ind i begrebet, og at der var ganske store forskelle i den brug, de gjorde af det. Og læser man videre i det forskningshistoriske anegalleri, giver efterfølgende generationer af religionsforskere mana-begrebet en hård medfart. Det var for bundet til et forladt evolutionistisk tankesæt, mente man, det var for bredt og blev af mange anvendt alt-forklarende og derfor ikke-forklarende, og endelig har konkrete mana-ord i Melanesien og Polynesien forskellig brug og form, som fagtermen ikke tilgodeser.

Debatten for og imod mana blev i Danmark nærmest mere hidsig end andre steder - desværre. I kampens hede blev det glemt, at mana blev til som et terminologisk supplement, der skulle modvirke ensidighed, snæversyn og faglig blindhed, og som - anvendt med omtanke - kunne medvirke til at åbne for analyser af fremmede religioners anderledes klassifikationssystemer (Tybjerg 2010, 134-42. 195-200. 266-88). Her vil jeg ikke gå nærmere ind på debatterne for og imod mana, men på den forsker, der introducerede mana som fagterm, englænderen Robert Ranulph Marett (18661943). Indførelsen af mana som teknisk term gjorde ikke Marett til forskningshistorisk hovedperson, hvad han heller ikke stræbte efter; han var noget så sjældent som en begejstret hverdagsakademiker, aktiv og virksom i en række administrative funktioner, en venlig og vågen kritiker af tidens yndlingsforestillinger og centralt placeret midt $\mathrm{i}$ - eller retter midt imellem - modsatrettede impulser i samtiden.

\section{Liv og forskning}

Marett kan på flere måder karakteriseres som en midt-imellem-forsker. Han er født på Jersey midt imellem England og Frankrig og er en vigtig formidler af durkheimianske synspunkter til engelsk antropologi. Han efterfulgte en af antropologiens grundlæggende skikkelser Edward Burnett Tylor i Oxford, efterfulgtes selv af den Durkheim-tro britiske antropolog Alfred Radcliffe-Brown og ligger dermed midt imellem århundredskiftets evolutionister og 1900-tallets funktionalister. Han er uddannet i klassisk filologi og filosofi, men mest kendt for sine antropologiske studier, og dermed også midt imellem filosofi og antropologi. Det sidste gik til på følgende måde. Da han som ung filosof i 1890 blev udnævnt til Fellow ved det prestigiøse Exeter College i Oxford, som han var knyttet til livet igennem, kastede han sig over at besvare en tre-årig prisopgave, The T.H. Green Moral Philosophy Prize, med titlen "The Ethics of Savage Races" udskrevet 1890 på Tylors foranledning. Marett fik prisen i 1893, kom tæt på Tylor og blev dermed i hvert fald fritidsantropolog. Hans hovedvirke var fortsat undervisning i filosofi; men han lagde gennem årene et stort arbejde i oprettelsen af antropologi som fag i Oxford, og han blev i 1910 udnævnt til Reader i 'Social Anthropology'; han bevarede sin interesse for filosofi og etik, satte 'comparative religion' i centrum af sit interessefelt og glædede 
sig i sine erindringer over at have kunnet "philosophize and anthropologize together, with a considerable overlap between the two interests" (Marett 1941, 322). William James taler i en anmeldelse om Maretts "very concrete sentiment of moral reality" (James 1903, 96; Marett 1941, 153) - en meget præcis karakteristik, som også dækker Maretts antropologiske virke.

"The Ethics of Savage Races" blev aldrig udgivet, og Maretts antropologiske ilddåb kom først 1899, da han ved et antropologmøde tog kritisk fat på Tylor og den samtidige antropologi med oplægget "Pre-Animistic Religion". "Pre-Animistic Religion" blev første kapitel i Maretts mest kendte og indflydelsesrige bog, antologien The Threshold of Religion, der udkom i 1909 og i en udvidet andenudgave i 1914. Artikel for artikel opbygger han sin kritik af henholdsvis Tylor og den anden af samtidens antropologiske koryfæer, James George Frazer - med indførelsen af mana-begrebet som konsekvens - og dermed blev han kendt.

\section{The Treshold of Religion: Kritik af Tylor og Frazer}

"Pre-Animistic Religion" retter kritisk opmærksomhed mod Tylors begreb 'animisme'. Sjæletro er vidt udbredt, og derfor er begrebet animisme frugtbart og nyttigt om en sådan tro på sjæle og ånder, skriver Marett. Men i mange tilfælde er der kræfter på spil, som ikke direkte tager form af åndevæsner. Maretts kritik af animisme går derfor ikke så meget på, hvad begrebet rummer, som på, hvad man kan risikere at overse, hvis det bruges som en generel term.

Animisme skal med andre ord suppleres. I et eksempel henviser Marett til, hvordan man i en sydafrikansk landsby styrter ud til en bakketop for at jage en truende orkan væk. Her er der næppe bestemte ånder på spil, men en levende trussel i form af orkanen - måske, skriver Marett, kan man her tale om en levendegørelse, Animatism. På en måde er det animisme i bred forstand, men Marett vil dog gerne reservere animisme til tilfælde, hvor der rent faktisk er sjæle og ånder på spil og foreslår derfor animatisme om resten."It is Animism in the loose sense of some writers, or, as I propose to call it, Animatism; but it is not Animism in the strict scientific sense that implies the attribution, not merely of personality and will, but of 'soul' or 'spirit', to the storm" (Marett 1909, 15).

I de følgende essays "From Spell to Prayer" og "Is Taboo a Negative Magic?" kritiserer Marett det meget håndfaste skel, som Frazer i andenudgaven af The Golden Bough (1900) lægger mellem magi og religion. Det er det eksklusive skel mellem magi og religion, som er målet for Maretts kritik - Frazers "oil-and-water theory" (Marett 1909, 77). Marett vil ikke afskaffe Frazers skelnen, som han finder nyttig og brugbar, blot pege på, at religion og magi er forbundne kar (Marett 1909, 34). Det gør han så ved at vise, at en besværgelse ikke virker direkte, som Frazer hævder. Dræber en magiker en fjende med et symbolsk spyd, vil der altid være behov for en forklaring af ikke-mekanisk karakter. "The spear did not do it of itself, but some occult power, whether in, or behind, the spear. Further, his own consciousness cannot fail to give 
him an intuitive inkling of what this power is, namely, his projection of will, a psychic force, a manifestation of personal agency, mana" (Marett 1909, 57).

\section{Maretts mana-begreb}

Marett havde som vist introduceret mana allerede i sine tidlige essays - uafhængigt af, men nogenlunde samtidig med durkheimianerne Henri Hubert \& Marcel Mauss i Frankrig. I "The Conception of Mana", Maretts foredrag ved den internationale religionshistorikerkongres i Oxford, 1908, samler han sin argumentation for mana som teknisk term og skriver igen, at han ikke dermed ønsker at skubbe animisme ud af begrebsapparatet. Mana- og sjæleforestillinger glider over i hinanden, og man kunne udmærket anvende termen animisme om hele felter, eller i virkeligheden endnu bedre mana om hele feltet (Marett 1909, 135). Skellet mellem animisme og mana er med andre ord ikke eksklusivt: men som Marett ser det, mener han, at det kan være en fordel at bevare animisme om sjæle og ånder med en vis individualitet og indføre mana som supplement, så også de mere upersonlige, overnaturlige udslag bliver synliggjort. Marett er tydeligvis optaget af at undgå et skarpt skel mellem animisme og mana, mens forholdet til Frazers magi-begreb spiller en mere tilbagetrukken, men derfor ikke mindre væsentlig rolle.

I Maretts argumentation for at indføre mana som teknisk term, indgår det tillige som et væsentligt argument, at man globalt også hos amerikanske indianere og afrikanske folk finder mana-lignende ord og begreber, som ikke kan oversættes animistisk. Når Marett - og i Frankrig Henri Hubert \& Marcel Mauss, "Esquisse d'une théorie générale de la magie" (1904) - vælger at basere sig på den britiske missionær Henry Codringtons beskrivelse af mana i The Melanesians (1891), tror jeg, det skyldes, at Frazer i sin redegørelse for skellet mellem magi og religion $i$ andenudgaven af The Golden Bough kommer med et langt citat fra netop Codrington. Mana er i Codringtons beskrivelse central både i magi og religion og rummer både personlige og upersonlige aspekter. Som Frazer ser det, er der tale om en "confusion of ideas" (Marett 1909, 59; Frazer 1900, I, 66-69). Nej, skriver Marett, der er på ingen måde tale om begrebsforvirring, men om et grundlæggende begreb - mana er brugbar som teknisk term netop fordi det ikke skiller det personlige fra det upersonlige (Marett 1909, 138; 1909a, 190ff.). Dermed falder Frazers oil-and-water skel mellem magi og religion væk, den Tylor'ske animisme får sit supplement, og mana-tabu indføres som ny minimumsdefinition på religion.

Skønt Marett eksplicit gør opmærksom på, at man i disse kulturer ikke opererer med 'naturlig' som i en vestlig kultur, mener han alligevel, at "mana in its essential meaning connotes ... the supernatural" (Marett 1909, 123); det har magt, og man skal omgå det med forsigtighed; derfor omgærdes det med tabueringer; det er "a conception of a specific aspect common to all sorts of things and living beings, under which they appear at once as needing insulation and as endowed with an energy of high, since extraordinary, potential" (Marett 1909, 131). Med andre ord, Maretts mana er 
'magt' eller 'kraft', ikke 'magten' som den religionsfænomenologisk orienterede hollandske religionshistoriker Gerardus van der Leeuw er tilbøjelig til at mene; og Maretts mana er både personlig og upersonlig, og ikke som Durkheim skriver en upersonlig kraft; i en vis forstand er Webers charisma mere dækkende for Maretts manabegreb, som også den tyske religionshistoriker Martin Riesebrodt er inde på (Riesebrodt 1997, 184), mens den tyske teolog og religionshistoriker, Rudolf Otto rendyrker de mere følelsesmæssige aspekter i sit begreb, 'det numinøse' (Otto 1922, 17).

\section{Maretts manabegreb - i brug}

Maretts kritik af Tylor og Frazer og påpegning af mangler og skævheder i tidens religionsvidenskabelige vokabular er overbevisende og præcis, og mana er på mange måder velfungerende som en teknisk term, der kan afhjælpe skævhederne. At Marett $i$ al venlighed og ydmyghed valgte blot at indføre mana som supplement til animisme og magi betød imidlertid, at efterfølgende diskussioner fastholdt et ufrugtbart, evolutionistisk skel mellem magiens upersonlige kræfter, som mana blev slået $\mathrm{i}$ hartkorn med, og animismens personlige sjæle - på trods af at Maretts pointe netop var at argumentere imod dette skel. Mana "... keeps in solution the distinction between personal and immaterial ..." skriver han og:

It must be noted that mana stands for that which, whilst quite immaterial, wavers between the impersonal and the personal; so that it can itself stand for a great deal to which we are apt to apply our terms 'soul', 'spirit', and the like, though there is never the implication of a wraith-like appearance (Marett 1909a, 193-194).

Marett var tæt på at bryde sin samtids paradigme, men for harmoniserende til at gøre alvor af et brud.

I en dansk sammenhæng kom bruddet med den evolutionistisk, fænomenologiske tænkemåde i religionshistorikeren Vilhelm Grønbechs skelsættende Soul or Mana, holdt som foredrag ved religionshistorikerkongressen i Leiden 1912 og udgivet som skrift i 1913, men uden det derfor fik international bevågenhed. "To the best of my understanding there is no such problem as soul or mana" (Grønbech 1913, 3) skriver han og udfolder den psykologi han har fundet i tekstmaterialet om de gamle nordboer. Her glider den personlige sjæl umærkeligt over i det mere upersonlige; "Here we see living and working a type of humanness that does not admit of being classified either under soul or mana, because it combines both forms of manifestation in one indivisible unity" (Grønbech 1913, 14). Selv brugte Grønbech ikke ét ord, men mange til at indkredse den nordiske psykologi, hvor sådanne skel ikke giver mening. Efterfølgende danske religionsforskere som Svend Aage Pallis og Arild Hvidtfeldt anvendte imidlertid mana som grundlæggende term i deres forsøg på at systematisere Grønbechs indsigter, men udsatte sig så for den kritik, der i almindelighed har ramt mana-begrebet som altforklarende og evolutionistisk nedladende. 
I dagens debat har de fleste valgt at indarbejde Maretts indsigt i forskellige varianter af animisme - den såkaldte "new animism" (Harvey 2013). Selv om disse forskere henviser til Tylor, ønsker de - som Marett - at komme ud over bindingerne til det europæiske sjælebegreb, som er mere eller mindre bundet til mennesker. Irving Hallowells artikel "Ojibwa Ontology, Behavior, and World View" (1960) har i den sammenhæng været overordentlig indflydelsesrig, ikke mindst hans formuleringer om magtfulde "other-than-human 'persons'". I et dansk perspektiv ligger Hallowells filologisk baserede analyse af Ojibwas ontologi metodisk tæt på Grønbechs; i kombinationen af personligt og upersonligt understreger Hallowell, som det fremgår af formuleringen, det personlige og argumenterer eksplicit mod den ensidige opfattelse af Maretts manabegreb som 'universal force', (Hallowell 2002, 43), en opfattelse, der som vist - heller ikke er dækkede for Maretts egen. Og hvad mana angår, er man i dag mest optaget af mana, som det anvendes i Oceanien - historisk og aktuelt - i New Age og i spil som fx Magic, dog med en betydelig forskningshistorisk interesse i mana som teknisk term (Tomlinson \& Tangan 2016). Så meget om senere udviklinger af det mana-begreb, som Marett introducerede.

Selv var Marett alt andet end dogmatisk i sin brug af mana - han kunne jo netop godt have brugt animisme om hele feltet og engagerede sig derfor heller ikke voldsomt i debatten. Hans engagement lå et andet sted. Hvad han brændte for, var følelser. Grundlæggende for ham var den kritik, han rettede mod Tylor og Frazer for en overdreven intellektualisme og urealistisk individualisme. Helt afgørende for Marett var det at indføre emotioner eller følelser i det religiøse felt og vise, hvordan de blev udfoldet i det sociale livs danse og ritualer. Samtidens religionsopfattelser var "too intellectualistic ... My own view is that savage religion is something not so much thought out as danced out; that, in other words, it develops under conditions, psychological and sociological, which favour emotional and motor processes, whereas ideation remains relatively in abeyance" (Marett 1914, xxxi). Marett vil belyse emotioner, og det vil han gøre socialpsykologisk, psykofysisk og ikke mindst evolutionistisk.

\section{Evolution og følelser}

'Awe' og 'uncanniness' er nøglebegreber i Maretts forståelse af religion. Som han ser det, kan alt, hvad der anses for at ligge uden for det normale og forventelige blive anset for ekstraordinært eller overnaturligt (Marett 1909, 8) og genstand for religiøse følelser: den "subtle thrill" (s. 4), den følelse af "Fear, Admiration, Wonder" (s. 10), af noget "uncanny" s. 23) eller den "awe" (s. 11) som er Maretts foretrukne betegnelse på kernen i det religiøse følelsesregister. 'Awe' er ikke ren frygt og rædsel, ordet er kun dækkende "if we admit Wonder, Admiration, Interest, Respect, even Love perhaps, to be, no less than Fear, essential constituents of this elemental mood" (s. 13).

Disse formuleringer er fra 1899 og rent psykologiske, men man kan i The Threshold of Religion følge, hvordan Marett i sit forsøg på at uddybe forståelsen af denne 'awe' 
denne følelse af noget 'uncanny' bliver mere og mere orienteret i retning af sociologi eller måske snarere socialpsykologi. Han ønsker en psykologisk forståelse, men vel at mærke "a Social, not an Individual, Psychology" (Marett 1909, 155), og den peger i en praktisk, motorisk retning. Mentalitet og samfund blandt 'de vilde' er, som han (lige lovlig kækt) udtrykker det 'mobbish'; også moderne samfund kender til massefænomener, men mere sporadisk - i sammenhængen knytter han 'mobbish' sammen med det, som allerede Robertson Smith havde vist, at ritualer og danse er af grundlæggende betydning i disse kulturer og føjer også en slags massepsykologisk forklaring til om, hvor let følelser spredes ved efterligning af bevægelser og udtryk:

Savage folk are mobbish; their mode of existence admits of no true privacy. Now, for those who are never away from the crowd, imitation is the mainspring of education; and the well-known law of crowds, that with them emotions propagate themselves more readily than ideas, is explained psychologically by the ease with which a mood can be acquired by imitating its outward expression. That ritual, or in other words a routine of external forms, is historically prior to dogma was proclaimed years ago by Robertson Smith and others. Yet Social Anthropology is but to-day beginning to appreciate the psychological implications of this cardinal truth (Marett 1914, 181).

Denne 'Mobbish-ness' taler han om i sin tiltrædelsesforelæsning i 1910 “The Birth of Humility", hvor også hans evolutionistiske argumentation skærpes. Uden Darwin ingen antropologi, skriver Marett i sin bog om antropologi (1908). Hvordan kan så religionens grundlæggende følelser af 'awe' og 'uncanniness' forklares evolutionistisk, dvs. overlevelsesstrategisk? Det mærkelige og farlige sætter nerver og fantasier i alarmberedskab hos dyr såvel som mennesker - 'uncanniness' er reaktionen - en slags faresignal.

Uncanniness ... corresponds to the mental twilight which circumscribes the experience of beast and man alike. Whatever is marginal is strange, and as such preys on the imagination and troubles the nerves ... Answering, then, to this root-feeling there is a world of awesome mystery through which all men walk at times, and the savage at frequent intervals. In this way, then, uncanniness represents negation, being a dangersignal and little more (Marett 1914, 184).

Han fortsætter argumentationen om faresignaler i et psykofysisk spor med at dyr, der er bange, enten flygter, trykker sig eller de overgiver sig ved at lægge sig fladt ned. Tilsvarende følelser hos mennesker samler psykologer under betegnelsen 'asthenic emotion' eller på jævnt engelsk "all forms of heart-sinking, of feeling unstrung" (Marett 1914, 186). Det er den ene side af det hellige - den negative, tabuerede. Men det hellige rummer andet og mere end denne "asthenic emotion" - det er også tiltrækkende og opløftende. "That which is uncanny, or, in an even more obvious way, that which is secret, attracts at the same time that it repels" (Marett 1914, 187); tabueringernes disciplineringer stabiliserer nerver og vilje og giver derved "spiritual relief". Han inddrager van Genneps på det tidspunkt spritnye bog om Les rites de passage og tolker overgangsriterne ud fra samme psykofysiske model som en bevægelse fra tabu til mana, fra kraftesløs fortvivlelse til nye energi-lag, ny vitalitet (Marett 1914, 200-201). 
Maretts brug af et evolutionistisk tankesæt, hvor de overlevelsesstrategiske fordele er afgørende for argumentationen, er rent spekulativ, men ligger ikke så fjernt fra den nutidige kognitionsforsknings evolutionspsykologiske overvejelser. Maretts lidt romantiske sprogtone er væk til fordel for en hyper-naturvidenskabelig, og Maretts overvejelser er langt mere spekulative end nutidens, men i en nutidig sammenhæng ville Marett med glæde - tror jeg - have gjort sig til talsmand for fx Justin Barretts overlevelsesstrategiske HADD - 'hyperactive agent-detection device' - tilbøjeligheden til ved den mindste raslen i græsset at se 'superhuman agencies' i omgivelserne for dermed at kunne bringe sig i sikkerhed (Barett 2006, 91ff.) og sikkert også godtage Pascal Boyers karakteristik af overnaturlige begreber som minimalt modintuitive (Boyer 2002, 58ff.). Det betyder ikke, at Marett er moderne, heller ikke at kognitionsforskerne er gammeldags, blot at 'nye' ideer næsten altid har 'gamle' aner.

\section{Sammenfatning}

Skal man prøve at sammenfatte Maretts indsats, så er han ikke nogen systembygger, men en glimrende systemkritiker: "I repudiate all the 'isms', if necessary with my last breath" (Marett 1941,152), skriver han med rette. Han bidrager til terminologiske overvejelser, men uden at blive rigid eller dogmatisk. Han henter inspiration fra mange, men uden det altid bliver helt klart, hvorfra inspirationen kommer. Der er noget muntert, legende i hans tilgang. "In sheer lightness of heart" er han som han skriver tilbøjelig "to sip from flower to flower, bee-fashion" (Marett 1941, 318). Men "bee-fashion" har han også stik og brod og er nærmest uovertruffen i sin evne til at finde de ømme punkter i samtidens religionsvidenskab. Hans forsøg på at afhjælpe de terminologiske begrænsninger i Tylors 'animisme' og Frazers 'magi' ved hjælp af mana-begrebet havde en kortvarig succes omkring år 1900, men blev efterfølgende genstand for voldsom kritik, og Marett blev nærmest glemt. Kritikken var ikke uberettiget, men skyldtes til dels, at Marett blev taget til indtægt for synspunkter, som han eksplicit argumenterede imod.

"Marett's reputation as an anthropologist has not survived and it would be difficult to identify any of his ideas that have had a lasting influence on his subject" (Rivière 2007, 56) skriver antropologen Peter Rivière - efter min mening med urette. Marett er bedre end sit rygte, og det samme gælder det mana-begreb, han introducerede, hvis ellers man gør sig den ulejlighed at læse, hvad Marett skrev. I dansk religionsvidenskab har 'mana' været anvendt som teknisk term med pædagogisk omtanke og med et betydeligt analytisk potentiale - helt i Maretts ånd - og i hvert fald til gavn og glæde for dem, der var så heldige at blive introduceret til religionshistorien gennem 'Arilds lille røde'. 


\section{LITTERATUR}

Ackerman, Robert

1990 J.G. Frazer: His Life and Work, Cambridge University Press.

Barrett, Justin $\mathrm{H}$.

2006 “Exploring the Natural Foundations of Religion”, in: D. Jason Slone, ed., Religion and Cognition: A Reader, Equinox, 86-98.

Bengtson, Dale R.

1979 "R.R. Marett and the Study of Religion", Journal of the Academy of Religion XLVII/4, 645-659.

Boyer, Pascal

2002 Religion Explained: The Human Instincts that Fashion Gods, Spirits and Ancestors, London: Vintage.

Codrington, Robert Henry

1957 The Melanesians: Studies in Their Anthropology and Folklore, HRAF Press (1891).

Frazer, James George

1900 The Golden Bough: A Study in Magic and Religion, 1-3, London: Macmillan \& Co. (1890).

Grønbech, Vilhelm

1913 Soul or Mana, København: V. Pios Boghandel.

Hallowell, Irving A.

2002 “Ojibwa Ontology, Behavior, and World View”, in: Graham Harvey, ed., Readings in Indigenous Religions, Continuum, 17-49. Reprinted from Stanley Diamond, ed., Culture in History,

Columbia University Press 1960.

Harvey, Graham

2013 The Handbook of Contemporary Animism, Routledge.

Hvidtfeldt, Arild

1961 Religioner og kulturer. Nogle hovedtræk af den almindelige religionshistorie, København: Munksgaard.

James, William

1903 "Review of H. Sturt, Personal Idealism", Mind, New Series 12 (45), 93-97. https://doi.org/10.1093/mind/XII.1.93

Kippenberg, Hans G.

1994 "Rivalry Among Scholars of Religions. The Crisis of Historicism and the Foundation of Paradigms in the History of Religions", Historical Reflections/Reflexions Historiques, 20 (3), 377402.

Marett, Robert Ranulph

1902 "Origin and Validity in Ethics", in: H. Sturt, ed., Personal Idealism. London: Macmillan \& Co., 221-287.

1909 The Threshold of Religion, London: Methuen \& Co.

1909a "The tabu-mana formula as a minimum definition of Religion", Archiv für Religionswissenschaft 12 Leipzig, 186-194.

1912 Anthropology, London: Williams and Norgate.

1914 The Threshold of Religion, Second and Enlarged Edition, London: Methuen \& Co.

1941 A Jerseyman at Oxford, Oxford: Oxford University Press.

Meyer, Birgit

2015 “How to Capture the 'Wow': R.R. Marett's Notion of Awe and the Study of Religion, Journal of the Royal Anthropological Institute (N.S.), 22, 7-26. https://doi.org/10.1111/1467-9655.12331

Otto, Rudolf

1922 Das Heilige. Über das Irrationale in der Idee des Göttlichen und sein Verhalten zum Rationalen, Breslau: Trewendt und Granier (1917).

Riesebrodt, Martin

1997 “Robert Ranulph Marett”, in: Axel Michaels, ed., Klassiker der Religionswissenschaft von 
Schleiermacher bis Mircea Eliade, Darmstadt: Wissenschaftliche Buchgesellschaft, 168-184.

Rivière, Peter

2007 "The Formative Years: The Committee for Anthropology 1905-38", in: Peter Rivière, ed., $A$ History of Oxford Anthropology. Methodology and History in Anthropology, Vol. 15, Bergbahn Books, 43-61.

Stocking, George W. Jr.

1995 After Tylor: British Social Anthropology 1888-1951, Athlone.

Styers, Randall

2012 "Mana and Mystification: Magic and Religion at the Turn of the Twentieth Century", Women's Studies Quarterly 40 (3-4), 228-45.

Sørensen, Jesper

2007 A Cognitive Theory of Magic, London: AltaMira Press.

Tomlinson, Matt \& Ty P. Tangan, eds.

2016 New Mana. Transformations of a Classic Concept in Pacific Languages and Cultures, Acton, ACT: Australian National University Press.

Tybjerg, Tove

2010 Religionsforskningen før og nu, I: Historiske rødder, redigeret af Armin W. Geertz \& Tim JensenGyldendal.

Wallis, Wilson D.

1957 "Anthropology Early in the Present Century", American Anthropologist, New Series 59 (5), 781 790. https://doi.org/10.1525/aa.1957.59.5.02a00030

Tove Tybjerg, lektor emerita, mag. art. Religionsvidenskab, Københavns Universitet 